\title{
Reflexión del discurso del bienestar y el desarrollo en el neoliberalismo. El caso en el sistema de salud colombiano
}

\author{
Reflection of well-being discourse and development in neoliberalism \\ ideology. The case in the Colombian health system
}

César Alberto Pazo Fernández ${ }^{\mathbf{1}}$

DOI: $10.1590 / 0103-1104202112902$

RESUMEN El objetivo de este artículo es analizar de manera crítica los procesos históricos que ha tenido la idea de bienestar en el campo de la salud, principalmente en Colombia. Desde la definición de salud propuesta por la Organización Mundial de la Salud a mediados del siglo XX, surgieron compromisos estatales que vincularon los modelos económicos en Latinoamérica, orientados a la garantía de mejores condiciones de bienestar social. Sin embargo, al examinar el proceso histórico de la idea de bienestar, es posible identificar los giros discursivos que han permitido el surgimiento, aplicación y reproducción de prácticas de poder institucional, justificadas en la búsqueda de mejores condiciones para el bienestar social. Ejemplo de ello son las reformas neoliberales a los servicios de salud, lo cual ha contribuido a la reconfiguración de los Estados y las relaciones sociales y a la naturalización de las desigualdades, como un asunto vinculado con la poca gestión de las personas para competir económicamente dentro de las reglas de juego del mercado. Para esto, se analizarán fuentes secundarias de índole política y normativa, así como algunos referentes teóricos que han contribuido a la discusión en torno a temas como el neoliberalismo, el bienestar y los sistemas de salud.

PALABRAS-CLAVE Bienestar. Colombia. Desarrollo. Discurso. Neoliberalismo. Salud.

\begin{abstract}
The objective of this article is to critically analyze the historical processes that social well-being has had in the field of health, mainly in Colombia. Since the definition of health proposed by the World Health Organization in the mid-twentieth century, State commitments have emerged that link economic models in Latin America to policies aimed at guaranteeing better social welfare conditions. However, when examining the historical process of well-being, it is possible to identify the discursive turns that have allowed the emergence, application, and reproduction of justified practices of institutional power in the search for better social welfare conditions. An example of this are neoliberal reforms to healthcare, which have contributed to the reconfiguration of States, social relations, and naturalization of inequalities as a matter of poor management of people to compete economically within the rules of the market. As it relates to welfare policies in Colombia, a secondary source of political and normative nature will be analyzed, as well as theoretical references that have contributed to the discussion around issues such as neoliberalism, well-being, and health systems.
\end{abstract}

KEYWORDS Well-being. Colombia. Development. Discourse. Neoliberalism. Health.

1 Universidad Nacional

Abierta y a Distancia

(Unad) - Bogotá

Colombia.

cesaralberto.pazo@gmail.

com 


\section{Introducción}

El presente artículo reflexivo deriva de la tesis de maestría de la autor, titulada 'Neoliberalismo y sistema de salud en Colombia. Discurso de bienestar de las Empresas Promotoras de Salud en Medellín, 2012-2018'. En las siguientes páginas, se analizaron elementos con contexto histórico que dan cuenta de los procesos y cambios que ha tenido la idea de bienestar como discurso en el campo de la salud. Además, partiendo de la definición de salud propuesta por la Organización Mundial de la Salud (OMS) en 1946, el tema ha presentado ciertas transformaciones que han despertado el interés social tanto como una necesidad de intervención como una oportunidad para el ejercicio de estrategias de poder por parte de actores económicos privados, que mediante las lógicas del mercado controlan el acceso al derecho a la salud. Así, el enfoque institucional por la mejora de las condiciones de vida ha contribuido a la adopción de modelos de desarrollo económico y humano que al día de hoy no solo han permeado la estructura de los sistemas de salud, sino que también han configurado las dinámicas sociales mediante la adopción de prácticas colectivas que legitiman el actuar de ciertas instituciones.

La principal línea metodológica de este artículo fue el análisis documental, mediante el cual se analizaron textos como la carta fundante de la OMS, el lineamiento del Fondo Monetario Internacional (FMI) para la reforma a los sistemas de salud de América Latina, la Constitución Política de Colombia de 1991 y la Ley 100 de 1993. Asimismo, el análisis se complementó con perspectivas críticas de diversos autores, quienes, a partir de temas como el neoliberalismo, las relaciones de poder y el desarrollo, han permitido develar las principales problemáticas de los sistemas sanitarios en Latinoamérica y, en especial, en Colombia.

De este modo, inicialmente, se exponen las implicaciones políticas que tuvo la salud como un asunto de bienestar, así como las connotaciones positivas y negativas en el ámbito social del nuevo papel de los Estados en la gestión sanitaria. Finalmente, se presentan las tensiones derivadas de los modelos de desarrollo y las reformas al sistema de salud colombiano, lo que ha conducido a ampliar las condiciones de desigualdad e inequidad social.

\section{La salud, un asunto de bienestar}

La actual comprensión de la salud desde una mirada institucional se gestó y posicionó en el contexto de la posguerra de la segunda guerra mundial. En este sentido, con el propósito de darle un enfoque más integral al concepto, en su acta de constitución, la OMS la definió como "un perfecto estado de bienestar físico, mental y social y no solamente la ausencia de afecciones y enfermedades"'. Con esta definición, la OMS marcó un punto de partida en la despersonalización de la salud. Del mismo modo, esta nueva acepción no solo tendría como resultado acciones de autocuidado individual, sino que también estaría articulada con una serie de determinantes sociales y elementos institucionales derivados del Estado, que, de manera conjunta, procurarían mejores condiciones de bienestar social.

A pesar de esto, la homogeneización de la definición de salud por parte de la OMS ha suscitado distintas opiniones a favor y en contra. Para autores como Navarro, uno de los problemas del concepto es de carácter epistemológico, puesto que

Asume que hay un consenso universal sobre lo que significan los términos clave de la definición, a saber, «salud», «bienestar» y «población». Esta universalidad, sin embargo, es apolítica y ahistórica. En otras palabras: la definición de la OMS evita el tema de quién define lo que es bienestar, salud y población, y presupone que «salud» es un concepto apolítico, conceptuado científicamente, que se aplica a todos los grupos sociales y a todos los períodos históricos por igual. Evita, pues, el problema epistemológico del poder ${ }^{2}$. 
Por otro lado, el mismo autor resalta que hay algunos avances en el giro conceptual, al afirmar que es un paso progresista que no solo va más allá de entender la salud como un asunto estrictamente biológico y psicológico, sino que además es un tema de índole social. De este modo, las intervenciones sanitarias no deben ser exclusivas de los servicios asistenciales, sino también orientadas a aspectos relacionados con las condiciones de vida de las personas, tales como la vivienda, el empleo, el ambiente, la distribución de la renta, etc. Esto marcó así un punto de inicio para un movimiento internacional que, luego de la segunda guerra mundial, orientó acciones para mejorar las condiciones de vida de la población y estableció las bases para el surgimiento del estado de bienestar en Occidente.

A pesar de las posturas a favor y en contra de la universalización del concepto de salud, algo que se ha tornado un común denominador entre las formas de definirla en la actualidad es que la salud va más allá de lo biológico y se articula con las dinámicas sociales y los recursos físicos, económicos y humanos que, por medio de un nuevo acuerdo social, marcan los compromisos entre el Estado y la sociedad para el alcance de mejores condiciones de bienestar y vida digna ${ }^{3}$. En ese sentido, la participación del Estado tiene un papel fundamental en el alcance de los compromisos trazados en materia de salud pública, no solo por lineamientos políticos que puedan ser promulgados, sino también por el manejo de las condiciones y modelos económicos propios de cada contexto, que se convierten en determinantes de las brechas para el acceso a oportunidades de la población.

Sumado a lo anterior, la salud y la enfermedad, más allá de ser categorías científicas, son categorías de poder, debido a que tanto la práctica médica como las instituciones sanitarias están altamente influenciadas por el contexto social y político del que forman parte ${ }^{2}$. Así, los procesos de participación y resistencia social como práctica política son capaces de ir más allá de la objetividad científica para establecer nuevas visiones de asuntos que puedan enmarcarse entre lo sano y lo enfermo en el ámbito institucional. En ese sentido, la redefinición e institucionalización del concepto de salud a partir de la constitución de la OMS expresa las ideas de base para el surgimiento de los estados de bienestar, al transitar del derecho a la asistencia al de la salud y el bienestar social. Esto amplía el panorama de intervención estatal, al pasar de un enfoque preventivo a uno de promoción de la salud, de manera que los nuevos estados de bienestar asumen un nuevo reto en materia de políticas públicas y planificación ${ }^{4}$.

Este nuevo giro en el discurso institucional no solo marcó un antes y un después en las políticas sociales de los Estados, sino que también, como todo discurso institucional, generó efectos en su abordaje, al articular la salud como resultado del bienestar en las distintas dimensiones del ser. Esto desencadenó una serie de discusiones académicas en torno a la acción biopolítica de los Estados y sus modelos económicos, debido a que, a partir de la nueva forma de ver y abordar la salud, eran más las condiciones de la vida cotidiana que determinaban las enfermedades y en las cuales los gobiernos tenían la responsabilidad de intervenir y controlar, de modo que la salud dejaba de ser exclusiva de la medicina y la salud pública para entrar en un escenario de acción política.

\section{El bienestar y la biopolítica}

La vida biológica ha marcado siempre el horizonte de la vida política, así como esta última ha sido necesaria para el desarrollo de las relaciones humanas y la vida. Sin embargo, ha sido hasta finales del siglo XVII y XVIII que el conocimiento de distintos procesos sociales ha marcado más la relación entre los aspectos políticos de la sociedad con la vida. Esto era contrario a la antigua visión griega, en la que la vida política no formaba parte de la vida biológica y viceversa, y fue solo hasta la modernidad en que la relación entre ambas 
esferas se tornó más estrecha. Asimismo, y como lo explica Esposito ${ }^{5}$, esta cercanía es progresiva y pasa por dos momentos cruciales. Por un lado, la transición del paradigma de la soberanía al de gobierno y, por otro lado, el surgimiento de la biología como disciplina a finales del siglo XVIII.

El surgimiento de la biología como disciplina y como ciencia contribuyó al desligue del pensamiento religioso y antropocéntrico, para reconocer al hombre como una especie más, que habita en contacto con otras especies, y transversalizado por fuerzas que escapan a la razón y responden al instinto. Por lo tanto, se cuestionó la supremacía y autonomía del hombre en la creación y manejo de instituciones como la democracia, y se tomó como punto de referencia al bios, como fuerza que está más allá de toda connotación jurídica y política ${ }^{5}$. Sin embargo, la posterior relación de interacción entre la vida y lo político no siempre involucró un compromiso estatal para el mejoramiento de las condiciones de vida.

Durante mucho tiempo, el interés hacia la salud estaba limitado por el cuerpo físico y su importancia en los procesos de industrialización y producción de bienes. De esta forma, la salud era valiosa desde el punto de vista social, en función de las dinámicas económicas en las que el cuerpo era visto solo como parte de la fuerza de trabajo. Foucault ${ }^{6}$ describió tres formas en que la consolidación entre política y vida toma lugar antes de convertirse en lo que es hoy día: en un primer momento, la medicina de Estado, que surgió en Alemania en el siglo XVII mediante el impulso de la policía médica como práctica 'medicalizada' para el mejoramiento de la salud de la población. A través de esto, el Estado inició su control en la enseñanza de la medicina y concesión de títulos para normalizar el ejercicio de la profesión, con el cual surgen también ministerios y organismos estatales para el control y la promoción de la medicina. Un fundamento filosófico característico de esta forma de medicina estatal es que iba más allá de ver a los individuos como fuerza laboral, para reconocerlos como fuerza de
Estado que podía hacer frente a los conflictos económicos y políticos frente a sus aliados.

La segunda forma de medicina descrita por Foucault, es la medicina urbana, desarrollada en Francia en el siglo XVIII y que, contrario a Alemania, no era impulsada por el Estado, sino por los mismos procesos de urbanización, que despertaban la preocupación del Estado por la higiene pública de las urbes. Allí empezaron a identificarse los espacios amenazantes para la sanidad, a aplicarse acciones de aislamiento y cuarentena y a reorganizar las fuentes de agua o corredores de aire, que, de paso, moldearon la forma de planificar las ciudades.

Finalmente, la medicina de la fuerza laboral fue la última forma en que se expresó la salud pública en el Estado desde sus orígenes. Esta fue promovida por el Estado inglés para la intervención de la clase obrera y de los pobres. A partir de allí, surgió una nueva forma de control, intervención y sesgo del Estado en lo social, puesto que se consideraba que la interacción entre ricos y pobres representaba un problema para la sanidad, de modo que el poder político intervino en el derecho a la propiedad y a la vivienda privada y dividió los sectores urbanos en zonas de ricos y de pobres.

La salud, como resultado de las condiciones de vida y el desenvolvimiento de los individuos con el trabajo, la vivienda, el empleo y el medio ambiente, va más allá del enfoque preventivo que la medicina tenía hasta inicios de la segunda mitad del siglo XX. Con el giro discursivo y la promulgación de la Declaración Universal de los Derechos Humanos (DUDH), no solo el acceso a los servicios sino también el bienestar en sí mismo pasaron a ser un derecho fundamental y exigible de las poblaciones a sus gobernantes. Por ende, se constituyeron en una nueva responsabilidad del Estado de orientar las acciones necesarias para garantizar, medir y controlar este derecho y establecer indicadores tanto en lo macrosocial como en lo individual.

Así que el nuevo papel del Estado en las condiciones determinantes del bienestar adquirió connotaciones tanto positivas como negativas con su participación en los asuntos 
de salud pública. Por un lado, asumió un papel facilitador en las condiciones sociales en las que nace y vive la gente, y, por otro lado, ese mismo papel generó un criterio controlador de las mismas condiciones. En otras palabras, la despersonalización en el nuevo discurso de la salud y el bienestar le permitió al Estado decidir y aplicar mecanismos para entenderlos, medirlos y controlarlos, así como las formas en que deben ser intervenidos los problemas derivados de la enfermedad. Esta ambigüedad, entonces, se convirtió en un nuevo escenario biopolítico, en el que es cada vez más importante la incidencia en la vida del poder del Estado y de las instituciones.

Según Tejeda ${ }^{7}$, uno de los asuntos cruciales de la biopolítica es la autoridad que ejercen las estructuras de poder sobre los individuos. Si bien esto no es un asunto nuevo, sí puede ser vista como contemporánea la forma en que las instituciones tanto del Estado como del mercado ejercen control y participación en la salud de las poblaciones.

Así, los objetivos y las estrategias surgidos a partir de la posguerra de la segunda guerra mundial - orientados al bienestar y la mejora de las condiciones de vida, como es el caso de la reducción de la morbilidad, la mortalidad, el aumento de la expectativa de vida y el acceso a servicios asistenciales - son producto del involucramiento del poder estatal en las poblaciones. Sin embargo, este involucramiento en los asuntos sociales no partió únicamente del giro discursivo de la redefinición de la salud y su despersonalización a partir de la constitución de la OMS, sino también del compromiso adquirido en la DUDH, lo cual posibilitó la transición de lo particular a lo general. Esto significa que ya no se limitaba solamente a aquellos grupos sociales más cercanos a las instituciones o con mayor poder económico, sino que la universalización de los derechos ampliaba el alcance a todos los grupos sociales.

En este orden de ideas, y como lo describe Tejeda ${ }^{7}$, a través del discurso del bienestar la biopolítica muestra un lado que en apariencia puede verse amable o positivo, al mostrar por parte de las instituciones de poder un interés y preocupación por los asuntos en materia de bienestar y salud, derechos humanos y respeto al individuo y a las comunidades. Por otro lado, el nuevo giro discursivo abre la acción biopolítica desde una mirada homogénea, en la cual la salud se entiende en todas las sociedades por igual, con lo cual las estrategias institucionales para controlar e intervenir los determinantes sociales de la salud parten del desconocimiento de las miradas particulares y multiculturales de los distintos grupos sociales.

\section{Del discurso del bienestar al discurso del desarrollo en el sistema de salud colombiano}

Entre las décadas de los cincuenta y los ochenta, Latinoamérica adoptó un modelo de desarrollo basado en la sustitución de importaciones, más conocido como modelo cepalino, en el marco de las ideas de desarrollo basadas en el crecimiento económico. Su característica principal eran el cierre de los mercados nacionales a los productos de origen externo y el incremento de las industrias locales que exportaban materia prima y manufacturas hacia los países industrializados. Si bien en un principio se evidenciaron crecimientos en la región de hasta un 7\%, las crisis derivadas del aumento en los precios del petróleo y las relaciones comerciales con los países del norte pusieron en jaque la vulnerabilidad de la región en la aplicación de la estrategia centro-periferia ${ }^{8}$.

En medio de las crisis de desempleo e inflación de la década de los setenta y los ochenta, servicios sociales como la salud, administrados por el Estado colombiano, representaban grandes cargas económicas y administrativas?. Asimismo, la inversión del Producto Interno Bruto (PIB) entre 1980 y 1990 era de casi el $6 \%$, del cual el $50 \%$ protegía a menos del $20 \%$ de la población que era perteneciente a las 
entidades de seguridad social. A su vez, el $50 \%$ restante debía distribuirse en el 80\% de población restante no asegurada ${ }^{10}$. En este contexto, es posible evidenciar que la salud $y$, en general, la seguridad social en Colombia ha dado pasos lentos desde sus inicios en la segunda mitad del siglo XX.

Ante este panorama del modelo cepalino y las presiones internacionales, empezaron a manifestarse nuevas propuestas en el escenario internacional para reformar el sistema económico de América Latina. En los fundamentos de pensadores como Friedrich Hayek y Milton Friedman, comenzó a gestarse y posicionarse en la década de los ochenta el conocido modelo económico neoliberal que, con la justificación de resolver los problemas económicos de la región y promover el desarrollo, terminó por desarticular a mayor escala la relación de intervención entre el Estado y los programas sociales.

De esta manera, el neoliberalismo se fue estableciendo como nuevo modelo económico internacional con base en principios como el Estado de derecho como tarea del gobierno, libertad de precios en el mercado, privatización de servicios brindados por el Estado, reducción del gasto social, entre otros ${ }^{11}$. Sumado a esto, Montoya describe tres aspectos en los que, a partir de los noventa, las ideas neoliberales se materializaron en la forma de gestar el Estado colombiano:

En lo político con la apertura y adecuación de los canales institucionales de expresión y participación ciudadana; en lo administrativo, con el ordenamiento y racionalización de las instituciones territoriales de gestión de asuntos públicos; y en lo económico, con la redefinición del papel del Estado en la economía12.

Por tanto, la nueva ideología orientó la desarticulación de las intervenciones estatales en sectores sociales como la salud y la educación para que, con poco o nulo control, estos escenarios tuvieran vía libre para convertirse en nuevos instrumentos de acumulación de capital.
Esta capacidad del neoliberalismo de penetrar y moldear las esferas de lo político, económico y social es lo que Laval y Dardot ${ }^{13}$ denominan como una nueva racionalidad del mundo. Esto debido a que, como ideología, discurso o práctica, no solo ha reestructurado el modelo económico y los lineamientos políticos de los gobernantes, sino que, además, ha redefinido el pensamiento y la conducta de los mismos gobernados. Por ende, esta nueva expresión del capitalismo ha llevado a las sociedades a materializar, legitimar y perpetuar a sí misma los problemas de desigualdad e inequidad que genera. De igual forma, esta nueva lógica de competencia va más allá de la apropiación del capital y de la reducción del Estado: lo conquista, lo domina y este deja a disposición de los grandes poderes económicos las bases políticas y normativas para facilitar que los campos de intervención social, que previamente eran responsabilidad del Estado, se conviertan en un elemento mercantil en el que priman la competencia y rentabilidad económica sobre el interés de bienestar social que este pueda generar.

Ahora bien, en el caso colombiano, el discurso neoliberal comenzó a manifestarse a principios de los años noventa, producto de las presiones internacionales surgidas a finales de la década anterior. Sin embargo, los nuevos ajustes políticos acarrearon contradicciones normativas que pusieron en choque los fines del Estado con los medios de los que se iba a valer para su alcance. Por un lado, las reformas constitucionales ratificaban el compromiso social y la garantía de los derechos fundamentales como la razón de ser del Estado. Por otro lado, la adopción de las reformas dictadas por el Banco Mundial y el FMI establecieron un determinante económico para el acceso a los programas de bienestar social, que ahora estaban mediados por la privatización del mercado. Las paradojas de la idea del bienestar empezaron a emerger en este nuevo proyecto económico, que en su origen culpabilizó al Estado por su ineficiencia para el alcance de mejores condiciones de bienestar 
y justicia social, y que se vendió a sí mismo como una mejor alternativa para el alcance del desarrollo.

\section{Neoliberalismo y sistema sanitario en Colombia}

Probablemente, el primer documento en que se materializó el discurso neoliberal para la reforma de los sistemas sociales fue el editado por el Banco Mundial, con el título: 'El financiamiento de los servicios de salud en los países en desarrollo. Una agenda para la reforma', publicado en 1987. El texto se convirtió en un diagnóstico de los problemas de solvencia económica que enfrentaban los sistemas sanitarios, y ofreció una serie de elementos para una reforma política que garantizara la eficiencia de los servicios sociales ${ }^{14}$. El primer argumento al que recurre el artículo es que el Estado de los países Latinoamericanos era incapaz de cumplir con los objetivos de bienestar social, debido a que el gasto público era demasiado elevado y poco eficiente. Por lo tanto, sugirió que estas responsabilidades se delegaran en el sector privado (denominado en el artículo como el 'sector no gubernamental'), el cual podía ofrecer una mejor gestión de los recursos y un mayor alcance de las metas en materia de salud y bienestar para la reducción de inequidades.

La estrategia inicial de los analistas que redactaron ese artículo era la contrastación, y aludieron a que el éxito que han tenido los países desarrollados en materia de salud es proporcional a la gran inversión pública que se realizaba para los servicios sanitarios. Contrario a eso, los países en vías de desarrollo pretendían replicar las estrategias de los más fuertes económicamente, pero bajo una inversión menor, la cual, a su vez, era producto de las crisis económicas que experimentaban en las décadas de los setenta y los ochenta.

El segundo argumento que se evidencia es la visión economicista que inicialmente determinaba que las diferencias en indicadores de salud entre países ricos y pobres está exclusivamente determinada por el monto de inversión, el cual deja de considerar aspectos administrativos, gestión social y condiciones de contexto que influyen como elementos diferenciadores y que, de ser intervenidos de manera adecuada, podrían significar una diferencia sustancial en los indicadores analizados.

Así las cosas, el análisis termina de hacer su problematización, al sustentar que, para que los Estados subdesarrollados pudieran responder a los problemas económicos y a las deudas externas en las que estaban involucrados, era necesario liberar parte del gasto social en salud, el cual más tarde podría ser invertido en asuntos más relevantes para la economía. De esta manera, el hilo discursivo en el cual se tejió la problematización de los sistemas de salud en los países no desarrollados denotó una responsabilidad gubernamental por los problemas expuestos. Ante esto, se ancló en lo público la culpa por las desigualdades e inequidades en materia sanitaria, que se apoyó una vez más en la contrastación con los países ricos, en los que no solo ha habido mayor inversión, sino que, además, los mejores indicadores médicos se obtienen en las clases sociales altas dispuestas a pagar por servicios privados para la atención particular.

En el esquema mencionado, las estrategias propuestas por el Banco Mundial en 1987 para las reformas políticas evidencian la génesis de las estructuras actuales de los sistemas sanitarios en América Latina y, en particular, en Colombia. La primera estrategia estaba orientada al cobro de aranceles a los usuarios. Así, el acceso a medicamentos y servicios debía estar respaldado mediante sistemas de recaudos tributarios que devolvieran recursos económicos al sistema y redujeran el uso de tratamientos de alto costo. Un ejemplo de ello en el actual sistema de salud colombiano se evidencia en el mecanismo de cobro de los copagos, las cuotas moderadoras e incluso las mismas cotizaciones al sistema.

Igualmente, en el cobro de aranceles está incluida la necesidad de expedir certificados 
de pobreza a las personas, con el fin de identificar a aquellos grupos sociales que merecen reducción en el pago arancelario o subsidios de parte de las clases altas. Esto ocurre aun cuando el sesgo en la prestación de los servicios solo beneficiaría a aquellos con mejor capacidad de pago de los servicios de salud privados para retornar el acceso a los servicios médicos, como un asunto de caridad más que como un derecho al que se pueda acceder por el compromiso de los Estados de brindar mejores condiciones de bienestar social. La aplicación directa de este tipo de certificado de pobreza es comparable en el contexto nacional con el Sistema de Identificación de Potenciales Beneficiarios de Programas Sociales (Sisbén) que, de acuerdo con el nivel socioeconómico de las personas, determina la capacidad de acceder a los beneficios sociales públicos.

La segunda estrategia fue orientada al uso de seguros de protección frente a riesgos. Ante la imposibilidad de las personas de pagar la totalidad de los costos de los servicios médicos o de los gobiernos de asumir esa carga, el artículo en mención del Banco Mundial sugiere estimular un mercado privado que ofrezca protección a las familias de las pérdidas financieras que se puedan generar por una enfermedad. La justificación detrás de esta propuesta era que, al ser las personas las encargadas de responder por el pago de los seguros y parte del costo de los servicios, se generaría de manera automática una cultura de autocontrol en la demanda de atención médica, que estimularía el ahorro en los gastos del sistema.

La anterior es una afirmación muy poco fundamentada en un contexto como el colombiano, en el que resulta absurdo suponer que las personas están en capacidad de pagar por aquello que necesitan, sobre todo cuando en el momento de las propuestas, el país atravesaba por una crisis financiera en la que el pago individual de los servicios implicaría en sí mismo, más que una oportunidad de mejora, una barrera para el acceso a los servicios. Sumado a esto, sugiere que, entre más amplio fuera el mercado de seguros, mayor control habría de los precios al promoverse la competencia por el mercado. Dicha propuesta figuró como lineamiento inicial para el surgimiento de las Empresas Promotoras de Salud (EPS).

Una vez más, la propuesta trazaba el camino para que la salud como un elemento fundamental para el bienestar fuera parte de un asunto mercantil, en el que la competencia por el acceso y oferta a la atención médica establecía reglas de juego económicas que favorecerían principalmente a las élites sociales.

Más tarde, lo que inició como un diagnóstico y una propuesta por parte del Banco Mundial en 1987 terminó por convertirse en política económica por medio de los lineamientos del llamado Consenso de Washington. A partir de las nuevas reglamentaciones establecidas por parte de organismos económicos internacionales, este consenso pretendía generar un ambiente de unificación en los mercados internacionales mediante reformas caracterizadas por la reducción en el tamaño del Estado, el fortalecimiento y la expansión del sector privado, la apertura a la inversión extranjera y más garantías para los derechos de propiedad privada ${ }^{15}$.

Por otra parte, distintas críticas suscitaron en torno al nuevo escenario. Por un lado, las nuevas estrategias de privatización y reducción del Estado no dejaban claro de qué manera estas reformas reducirían los problemas de deuda y brecha económica que se pretendían resolver, y, por otro lado, era prácticamente invisible el tema de la equidad, sobre todo ante un nuevo escenario de privatización que demandaba mejores condiciones económicas del mercado, y que buscaba expandirse en un contexto social y económico de crisis presupuestaria.

Esto último, a su vez, se vio reflejado en los cambios de privatización y descentralización de los sistemas de salud de América Latina, que, a través de su nueva estructura de competencia regulada, marcó un inicio para un cambio sustancial en la forma de concebir la salud en la sociedad. Esto se dio inicialmente con la deslegitimación colectiva hacia lo público y luego con la naturalización de 
la fragmentación social, que en el campo de la salud puede reflejarse en la aceptación de barreras económicas de acceso, en las cuales el bienestar prima como un derecho de las élites en capacidad de costear los servicios médicos, mientras que para las clases pobres sin capacidad de pago la salud queda relegada como un favor ${ }^{16}$.

\section{Las reformas en Colombia}

Las mismas reformas constitucionales y normativas de principios de los noventa en Colombia dan cuenta de los cambios políticos que empezaron a emerger en el país, y de cómo el discurso de corte neoliberal penetró en la esfera estatal y en la conciencia colectiva a través de un manto de bienestar que lo define como institucionalmente necesario y socialmente aceptable dentro de los distintos actores que lo reproducen y progresivamente lo legitiman. Poco a poco, el desvanecimiento de la confianza hacia lo Estatal y el fortalecimiento del interés por lo privado establecieron un nuevo orden de cosas que ratificaba la competencia de los sujetos como un asunto de derechos. Esto dejó sobre la base social la aceptación de la desigualdad y la inequidad, dado que solo los más capaces podían acceder a los beneficios del sistema de salud y las ventajas del desarrollo.

En la Constitución de 1991 la salud no figura propiamente como parte de los derechos fundamentales, sino como un servicio público, cuya acepción de 'fundamental' está ligada con los casos en los que se violen aquellos derechos de primera categoría, como el derecho a la vida. Aunque la seguridad social es reconocida como un derecho irrenunciable de todos los ciudadanos, en especial aquello con mayor vulnerabilidad económica, física o mental, también está claro que la cobertura y prestación del servicio no será exclusiva del Estado y que el sector privado puede ser partícipe del sistema de sanitario con el objetivo de mejorar la cobertura. Asimismo, la reforma era enfática en que los cambios estaban orientados a aumentar el bienestar general, el mejoramiento de la calidad de vida y la solución de necesidades insatisfechas de salud como finalidades sociales del Estado.

Sin embargo, con la nueva Constitución comienzan a surgir dicotomías que ponen en entredicho la capacidad gubernamental de garantizar la igualdad e irrenunciabilidad social de la salud como derecho. Por un lado, la transición del Estado de Derecho a la definición de Estado Social de Derecho, en cuya concepción político-social fue elevado a deber constitucional el suministro de la prestación de servicios asistenciales a la comunidad, que, más allá de ser un favor institucional, fue un logro jurídico de los ciudadanos por su propio beneficio"1.

Por otro lado, está el cuestionamiento con respecto a las garantías para el cumplimiento de este compromiso, sobre todo cuando en el marco de la misma reforma se dio paso a la libertad de mercado en torno a los servicios asistenciales, lo que dejó a las instituciones públicas al margen de la regulación y supervisión, y redujo así su participación como prestador directo. En ese orden de ideas, ¿̨cuál puede ser el resultado de la búsqueda de igualdad, bienestar y vida digna, cuando el escenario institucionalmente construido pone como parte del juego intereses sociales versus intereses económicos en un contexto de inequidad? La situación se torna más compleja con la reforma al sistema de salud mediante la Ley 100 de 1993, que ratifica el papel dominante del sector privado como un controlador y determinante de las condiciones de vida de la sociedad desde principios de los años noventa hasta la actualidad.

\section{Ley 100 de 1993. ¿Neoliberalismo y bienestar?}

Por medio de la Ley 100 de 1993 se organizó el actual sistema de salud en el marco del Sistema General de Seguridad Social Integral (SGSSI), 
que reglamentó el régimen pensional, el de la salud y el de riesgos profesionales ${ }^{16}$. El nuevo modelo puso a disposición de la población un plan de beneficios que, esencialmente, describía aquellos servicios y procedimientos a los que se podía acceder mediante cobertura pública a través de las distintas instituciones que pertenecieran al sistema. Sin embargo, estas instituciones eran principalmente de carácter privado, personas jurídicas constituidas por agentes particulares, con el fin de garantizar el aseguramiento de la población, la cobertura y la atención a los demás prestadores de servicios, tales como clínicas y hospitales.

Aunque las EPS son en principio de tipo privado, su subsistencia financiera depende de recursos públicos girados por la nación para el aseguramiento de cada uno de sus afiliados. Por lo tanto, el dinero recibido debe distribuirse entre el pago de los servicios médicos prestados, el gasto administrativo de su operación y las utilidades netas que espera percibir como agente privado. En esta nueva estructura es posible identificar la materialización de las propuestas realizadas por el Banco Mundial en 1987, así como los fundamentos del pensamiento neoliberal. Y es que hay reducción del tamaño del Estado, al delegar un bien común a actores no gubernamentales, ofrecer facilidad para el desarrollo de la empresa privada y disponer de un bien común como parte de la oferta del mercado.

Asimismo, la ley mencionada se articula en función de principios como la eficiencia y la universalidad, los cuales definen el carácter ético y el compromiso social que justifica su razón de ser. A pesar de esto, ¿̨qué puede develarse en tales principios? En primer lugar, al hablar de eficiencia, la misma ley hace referencia al manejo adecuado de los recursos financieros, administrativos y técnicos, los cuales, de entrada, no son orientados en totalidad para el cumplimiento de sus fines, porque parte de estos deben dirigirse hacia la garantía de las aspiraciones de rentabilidad financiera que los administran. Además, los recursos restantes, que son girados a los prestadores directos del servicio (clínicas y hospitales), no son suficientes para solventar la totalidad de la atención médica suministrada, lo cual deviene en retrasos de la atención, poca oferta hospitalaria, negación de servicios y cierre de las instituciones protagonistas de la atención médica asistencial.

En segundo lugar, el principio de universalidad es un poco más problemático que el anterior. Se define como la atención a toda la población sin ningún tipo de discriminación en todas las etapas de la vida. Para que esto sea aplicable y alcanzable, de entrada, se necesitaría una estructura alterna del sistema, debido a que el modelo actual de aseguramiento realiza una fragmentación entre usuarios con capacidad de pago y población pobre. No obstante, trazar una diferencia entre unos y otros determinada por las condiciones económicas de sus afiliados es, en sí mismo, una barrera de fragmentación social que perpetúa la estructura de clases en la población.

De igual forma, la universalidad es defendida actualmente en términos de aseguramiento. La defensa que hace el sistema de su importancia actual es que, con respecto al sistema anterior, este sí ha alcanzado un porcentaje de aseguramiento cercano al $100 \%$ de la población. Sin embargo, esta afirmación es cuestionable, en la medida en que la condición de afiliado no está directamente relacionada con el acceso a los servicios ni mucho menos con que estos sean de calidad. Problemas con la negación de servicios, retrasos en la atención y complicaciones por enfermedades prevenibles han puesto en entredicho la capacidad de gestión del sistema actual.

Por tanto, no solo la estructura del sistema de salud es un reflejo de la materialización del pensamiento neoliberal en el caso colombiano. Los distintos grupos sociales naturalizan el discurso y lo convierten en práctica a través de la construcción de hábitos que perpetúan el funcionamiento de estas instituciones de poder y establecen relaciones de competencia entre los mismos individuos. 


\section{Conclusiones}

El análisis del contexto histórico del sistema de salud ha permitido identificar que el giro discursivo que facilitó a la institucionalidad apropiarse de la idea de bienestar ha sido la definición del concepto mismo de salud por parte de la OMS. A partir de este momento, la determinación con respecto a lo que las sociedades necesitaban para estar bien y el modo de gestionar su alcance era desde la toma de decisiones de actores externos a las personas y a las comunidades. Si bien pudo representar en sus inicios una estrategia positiva que favoreció la comprensión de un mismo lenguaje para la administración de lo público y la búsqueda de condiciones equitativas de acceso a la salud y a los derechos humanos, también significó una oportunidad para el ejercicio del poder a través de mecanismos que veían en el proceso de salud y enfermedad e incluso en la misma vida la posibilidad para el ejercicio del control social. De este modo, el deseo por mejores condiciones de vida y el acceso a aquello que define el 'estar bien' estrechó la relación entre el horizonte biológico y el político mediante nuevas formas de interdependencia.

En ese sentido, la idea de bienestar, anclada a aquello que la institucionalidad estuviera en capacidad de aportar, abrió el camino para que la emergente idea de desarrollo, principalmente desde un enfoque económico, erigiera nuevas formas de apropiación de los servicios sociales como parte de los productos de competencia del mercado en el sector privado. Así, el acceso a la salud como elemento fundamental para el bienestar se enmarcó en estrategias de mercantilización que favorecen las condiciones para el acceso privilegiado de aquellos que estaban en capacidad de costearla, de acuerdo con su nivel socioeconómico. De esta manera, el poder relegado al sector privado, sometido a los lineamientos del modelo económico neoliberal, estableció unas reglas de juego que no solo definen que debía ser entendido como bienestar, sino que también configuró una nueva racionalidad social que legitimaba la necesidad de los actores privados para la provisión y satisfacción de las necesidades sociales.

\section{Colaborador}

Fernández CAP (0000-0003-2634-9246)* es el encargado de preparar el manuscrito. 


\section{Referencias}

1. Organización Mundial de la Salud. Constitución de la Organización Mundial de la Salud. Documentos Básicos. 2014. [acceso en 2020 abr 25]. Disponible en: http://apps.who.int/gb/bd/s/.

2. Navarro V. Salud Pública. Concepto actual de salud pública. 1997. [acceso en 2020 abr 25]. Disponible en: https://ifdcsanluis-slu.infd.edu.ar/sitio/material-de-estudio-del-ano-2013/upload/navarro.pdf.

3. Vélez A. Nuevas dimensiones del concepto de salud: El derecho a la salud en el Estado social de derecho. Rev Hacia la Promoción de la Salud. 2007. [acceso en 2020 abr 25]; 12(1):63-78. Disponible en: http://www. scielo.org.co/pdf/hpsal/v12nl/v12nla05.pdf.

4. Castillo CHM, Garrafa V, Cunha T, et al. El acceso a la salud como derecho humano en políticas internacionales: reflexiones críticas y desafíos contemporáneos. Ciênc. Saúde Colet. 2017 [acceso en 2020 abr 25]; 22(7):2151-60. Disponible en: http://www. scielo.br/scielo.php?script=sci_arttext\&pid=S1413$-81232017002702151 \& \operatorname{lng}=\mathrm{es} \& \operatorname{tlng}=\mathrm{es}$.

5. Esposito R. Vida biológica y vida política. Rev. pleyade. 2013 [acceso en 2021 jun 10]; 12(1):15-533. Disponible en: https://dialnet.unirioja.es/servlet/ articulo? codigo $=4703311$.

6. Foucault M. Historia de la Medicalización. Educ. Med. Salud. 1977 [acceso en 2020 abr 25]; 11(1):4-25. Disponible en: https://terceridad.net/Sistemasdesalud/Foucault,\%20M.\%20Historia\%20de\%20la\%20 medicalizaci\%F3n.pdf.

7. Tejeda L. Biopolítica, control y dominación. La biopolítica y las nuevas áreas de indagación. Espiral Estud. sobre Estado y Soc. 2011; 18(52):77-107.

8. De Currea-Lugo V. Salud y Neoliberalismo. Bogotá, D. C., Colombia: Universidad del Bosque; 2010.
9. Rocha A. Antecedentes históricos de la seguridad social en salud: parte de la construcción de un país sin memoria. Rev CES Odontol. 2010; 23(2):77-84.

10. Esguerra R. Aún no es hora de reformar la Ley 100. Colomb. Med. 1996; 27(2):77-85.

11. Guillén H. Los orígenes del neoliberalismo: del Coloquio Lippmann a la Sociedad del Mont-Pèlerin. Economiaunam. 2018 [acceso en 2020 abr 25]; 15(43). Disponible en: http://www.scielo.org.mx/pdf/eunam/v15n43/1665-952X-eunam-15-43-7.pdf.

12. Montoya A. Modelos y políticas de desarrollo en Colombia. Un análisis crítico del desempeño de la política económica. Medellín: Editorial Universidad Pontificia Bolivariana; 2004

13. Laval C, Dardot P. La nueva razón del mundo. Barcelona: Gedisa; 2010

14. Banco Mundial. El financiamiento de los servicios de salud en los países en desarrollo. Una agenda para la reforma. Washington: BM; 1987.

15. María Serrano JF. El “Consenso de Washington” ¿Paradigma económico del capitalismo triunfante? Rev. Fom. Soc. [internet]. 2000 [acceso en 2020 abr 25]; (217):28-45. Disponible en: https://dialnet.unirioja. es/servlet/articulo? codigo $=7604$.

16. Colombia. Ley 100 de 1993. Por la cual se crea el sistema de seguridad social integral y se dictan otras disposiciones. Colombia: Congreso de la República de Colombia; 1993.

Recibido en 16/06/2020 Aprobado en 19/11/2020

Conflicto de intereses: inexistente

Apoyo financiero: no hubo 